\title{
IN LIEU OF A PREFACE
}

What can be done about the state of classical music? In recent years it has sharply declined in popularity and cultural authority; the prospect of its slow disappearance is no longer unthinkable. The music has had advocates, of course, some of them eloquent, but few have asked forthrightly why and how classical music should still matter. That is exactly what this book does. Without pretension or mystification, Why Classical Music Still Matters looks for answers that can appeal both to lovers of this music and to skeptics. It describes the sources of the music's power in a wide variety of settings, from concert performance to film and television, from everyday life to the historical trauma of September I I. It affirms the value of classical music by revealing what its values are: the beliefs, attitudes, and meanings that the music has supported in the past and can support into the future. It shows the traits that make this music distinctive and that offer rich rewards to anyone willing to listen. 
The book also clears the air of old prejudices. It refuses to separate classical music from popular culture, or to argue about the superiority or inferiority of musical types, or to accept the idea that special knowledge or guidance is required to enjoy the music. Instead it makes an impassioned but not uncritical case for classical music on the basis of the unique things that the music can be, mean, and do. This is a deeply personal text that nonetheless seeks to argue with rigor and clarity. It is a book that treats classical music from Bach to Tchaikovsky, Chopin to Ligeti, as a living art that still has much to contribute to the art of living.

One practical note. Because it is essayistic - in a sense because it tries to be musical-this book does without footnotes. Citations appear at the end under the rubric "References," keyed to identifying words and phrases from the individual chapters. 